\title{
Margin Pemasaran Ikan di Kecamatan Insana Utara Kabupaten Timor Tengah Utara
}

\author{
Dance M. Selan ${ }^{\mathrm{a}}$, dan Agustinus Nubatonis ${ }^{\mathrm{b}}$ \\ ${ }^{a}$ Fakultas Pertanian, Universitas Timor, Kefamenanu, TTU - NTT, Indonesia. \\ ${ }^{b}$ Fakultas Pertanian, Universitas Timor, Kefamenanu, TTU - NTT, Indonesia.
}

\section{Article Info}

Article history:

Received 12 April 2016

Received in revised form 20 Juni 2016

Accepted 11 Juli 2016

\section{Abstrak}

Penelitian bertujuan untuk mengetahui 1) fungsi-fungsi pemasaran yang dilakukan nelayan dan pedagang perantara; 2) saluran pemasaran kan; dan 3) margin pemasaran ikan. Metode analisis data yang digunakan adalah deskripsi kualitatif dan analisis margin pemasaran. Hasil penelitian menunjukkan bahwa fungsi-fungsi pemasaran yang dilakukan oleh petani yakni fungsi penjualan, penyedia fisik dan fungsi informasi pasar. Sedangkan yang dilakukan oleh pedagang pemborong adalah fungsi pembelian, fungsi penjualan, fungsi penyimpanan, fungsi pengangkutan, fungsi pengolahan, fungsi pengadaan fisik, fungsi informasi pasar. Sedangkan fungsi pemasaran yang dilakukan oleh pengecer yaitu fungsi pembelian, fungsi penjualan, fungsi penyimpanan, fungsi pengangkutan, fungsi pengolahan, fungsi pengadaan fisik, fungsi grading, fungsi risiko. Terdapat lima saluran pemasaran yakni 1) Nelayan $\rightarrow$ Konsumen; 2) Nelayan $\rightarrow$ Pengecer Wini $\rightarrow$ Konsumen; 3) Nelayan $\rightarrow$ Pemborong Wini $\rightarrow$ Pengecer Kefa $\rightarrow$ Konsumen; 4) Nelayan $\rightarrow$ Pemborong Kefa $\rightarrow$ Pengecer Kefa $\rightarrow$ Konsumen; dan 5 ) Nelayan $\rightarrow$ Pemborong Atambua $\rightarrow$ Pengecer Atambua $\rightarrow$ Konsumen. Margin pemasaran yang terjadi berbeda-beda di setiap saluran pemasaran yaitu : (a) margin pemasaran ikan pada saluran II sebagai berikut : ikan Tembang Rp 150.000, ikan Kombong Rp 200.000, ikan Nipi Rp 250.000, ikan Tongkol Rp 300.000. (b) margin pemasaran ikan pada saluran III sebagai berikut: di tingkat pemborong ikan Tembang Rp 150.000, ikan Kombong Rp 200.000, ikan Nipi Rp 200.000, ikan Tongkol Rp 200.000, sedangkan pada tingkat pengecer ikan Tembang Rp 205.000, ikan Kombong Rp 180.000,ikan Nipi Rp 210.000, ikan Tongkol Rp 220.000. (c) Margin pemasaran pada saluran ke IV sebagai berikut: di tingkat pemborong ikan Tembang Rp 200.000, ikan Kombong Rp 250.000, ikan Nipi Rp 250.000, ikan Tongkol Rp 200.000, sedangkan di tingkat pengecer ikan Tembang Rp 150.000, ikan Kombong Rp 110.000, ikan Nipi Rp 150.000 dan ikan Tongkol Rp 180.000. (d) margin pemasaran ikan pada saluran V sebagai berikut: di tingkat pemborong ikan Tembang Rp 200.000, ikan Kombong Rp 250.000, ikan Nipi Rp 250.000 dan ikan Tongkol Rp 250.000, sedangkan di tingkat pengecer ikan Tembang Rp 160.000, ikan Kombong $\mathrm{Rp} 150.000$, ikan Nipi Rp 170.000 dan ikan Tongkol Rp 210.000. @2016 dipublikasikan oleh Agrimor.

\section{Fungsi Pemasaran}

Saluran Pemasaran

Margin Pemasaran

Ikan nelayan yaitu dari populasi nelayan sebanyak 58 orang seluruhnya digunakan sebagai sampel. Sedangkan metode snowball sampel digunakan untuk menelusuri setiap pedagang perantara yang terlibat dalam pemasaran ikan yang berasal dari Kecamatan Insana Utara. Data yang digunakan dalam penelitian in adalah data primer dan data sekunder, dimana data primer merupakan hasi observasi dan wawancara langsung dengan responden. Sedangkan data sekunder adalah data yang diperoleh dari instansi terkait seperti dinas perikanan dan kelautan, badan pusat statistik.

Metode analisis data yang digunakan adalah metode deskripsi kualitatif sesuai petunjuk Sugiyono, (2006) untuk menjawab tujuan pertama dan kedua, sedangkan untuk menjawab tujuan ketiga menggunakan metode analisis margin pemasaran sesuai petunjuk Sudiyono, (2002).

\section{Hasil dan Pembahasan}

\subsection{Gambaran Umum Lokasi Penelitian}

Kecamatan Insana Utara memiliki luas wilayah $53,84 \mathrm{~km}^{2}$. Secara administrasi batas-batas wilayah Kecamatan Insana Utara adalah: sebelah Utara berbatasan langsung dengan selat Ombai, sebelah Selatan berbatasan langsung Kecamatan Miomafo Timur, Kecamatan Insana Fafinesu dan Kecamatan Insana Tengah, sebelah Timur berbatasan dengan Kecamatan Insana Tengah dan Kecamatan Moenleu dan sebelah Barat berbatasan dengan Kecamatan Naibenu dan Negara Demokrat Timor Leste. Jumlah penduduk Kecamatan Insana Utara pada tahun 2013 sebanyak 9.112 jiwa, dengan rata-rata kepadatan penduduk sebesar 169 jiwa $/ \mathrm{km}^{2}$ dengan rincian 4.569 jiwa berjenis kelamin laki-laki dan 4.543 jiwa berjenis kelamin perempuan.

Sarana yang berkaitan dengan perikanan di Kecamatan Insana Utara yakni satu unit kantor UPTD (Unit Perikanan Terpadu Desa), dua lokasi penjualan ikan yakni di Aijao dan Temkuna. Sedangkan untuk penyediaan es sebagai bahan pengawet ikan hasil tangkapan dari nelayan dapat dibeli di kios-kios yang berada di sekitar pantai Wini. Transportasi menuju pantai Wini sangat menunjang karena garis pantai berdekatan dengan jalan umum Timor Raya sehingga para konsumen maupun pedagang perantara tidak kesulitan untuk membeli ikan di lokasi Aijao maupun Temkuna.

\subsection{Saluran Pemasaran}

Saluran pemasaran merupakan pola-pola pemasaran yang terbentuk selama pergerakan arus distribusi komoditi dari produsen ke konsumen akhir. Saluran pemasaran yang terbentuk selama penyaluran ikan dari nelayan di Kecamatan Insana Utara ke konsumen akhir dapat dilihat pada Gambar 1

Saluran distribusi merupakan salah satu komponen penting di dalam pemasaran untuk menyampaikan barang dan jasa dari produsen ke tangan konsumen dengan baik. Menurut Azzaino, (1982) margin pemasaran adalah perbedaan harga yang dibayar konsumen akhir untuk suatu produk dan harga yang diterima petani/produsen untuk produk yang sama. Berdasarkan hal tersebut, penting untuk dilakukan kajian tentang margin pemasaran ikan yang terjadi di Kecamatan Insana Utara kabupaten TTU. Tujuan penelitian ini adalah untuk mengetahui 1) fungsi pemasaran ikan; 2) saluran pemasaran ikan; dan 3) margin pemasaran ikan di Kecamatan Insana Utara.

\section{Metode}

Penelitian ini dilaksanakan di kecamatan Insana Utara, Kabupaten TTU mulai dari bulan Desember tahun 2015 sampai bulan Maret tahun 2016 Pengambilan sampel dalam penelitian ini dilakukan dengan 2 metode yaitu metode sensus sesuai petunjuk Sugiyono, (2006) dan metode snowball sampling sesuai petunjuk Subagyo, (2006) dimana metode sensus digunakan untuk

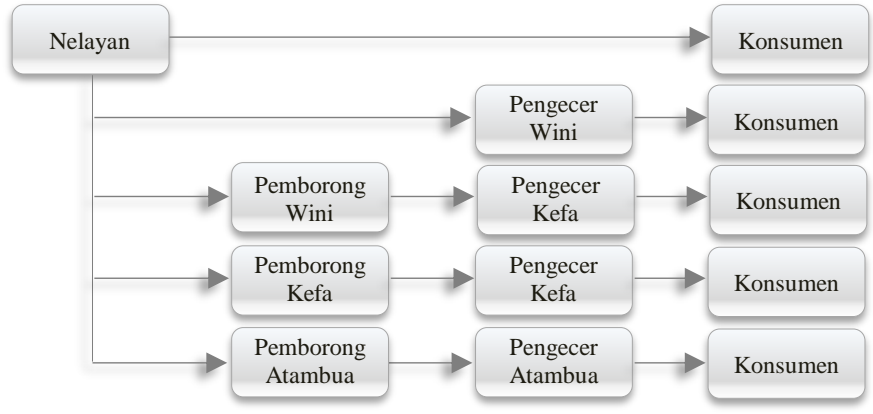

Gambar 1. Saluran Pemasaran Ikan 
Terdapat lima saluran pemasaran yakni 1) Nelayan $\rightarrow$ Konsumen; 2) Nelayan $\rightarrow$ Pengecer Wini $\rightarrow$ Konsumen; 3) Nelayan $\rightarrow$ Pemborong Wini $\rightarrow$ Pengecer Kefa $\rightarrow$ Konsumen; 4) Nelayan $\rightarrow$ Pemborong Kefa $\rightarrow$ Pengecer Kefa $\rightarrow$ Konsumen; dan 5) Nelayan $\rightarrow$ Pemborong Atambua $\rightarrow$ Pengecer Atambua $\rightarrow$ Konsumen

\subsection{Fungsi-Fungsi Pemasaran}

Fungsi-fungsi pemasaran merupakan semua jasa atau kegiatan dan tindakan yang diberikan dalam proses pengaliran barang dari tangan produsen ke tangan konsumen akhir. Fungsi pemasaran yang dilakukan oleh nelayan dan pedagang perantara berbeda seperti diuraikan dalam Tabel 1 .

Tabel 1. Fungsi-Fungsi Pemasaran yang Dilakukan oleh Nelayan dan Pedagang Perantara

\begin{tabular}{|c|c|c|c|c|c|}
\hline No & Fungsi-Fungsi Pemasaran & $\mathrm{N}-\mathrm{K}$ & $\mathrm{N}-\mathrm{PP}$ & $\mathrm{PP}-\mathrm{Pr}$ & $\operatorname{Pr}-\mathrm{K}$ \\
\hline \multirow[t]{3}{*}{1} & Pertukaran & & & & \\
\hline & a. Pembelian & & & $\sqrt{ }$ & $\sqrt{ }$ \\
\hline & b.Penjualan & $\sqrt{ }$ & $\sqrt{ }$ & $\sqrt{ }$ & $\sqrt{ }$ \\
\hline \multirow[t]{5}{*}{2} & Fisik & & & & \\
\hline & a. Penyimpanan & - & - & $\sqrt{ }$ & $\sqrt{ }$ \\
\hline & b. Pengangkutan & - & - & $\sqrt{ }$ & $\sqrt{ }$ \\
\hline & c. Pengolahan & - & - & $\sqrt{ }$ & $\sqrt{ }$ \\
\hline & d.Pengadaan fisik & $\sqrt{ }$ & $\sqrt{ }$ & $\sqrt{ }$ & $\sqrt{ }$ \\
\hline \multirow[t]{5}{*}{3} & Penyedia Fasilitas & & & & \\
\hline & a. Grading & - & - & - & $\sqrt{ }$ \\
\hline & b. Risiko & - & - & - & $\sqrt{ }$ \\
\hline & c. Informasi Pasar & $\sqrt{ }$ & - & $\sqrt{ }$ & - \\
\hline & d.Penyedia Dana & - & - & - & - \\
\hline
\end{tabular}

Keterangan: N : Nelayan; PP : Pedagang Pemborong; Pr : Pedagang Pengecer; $\mathrm{K}$ : Konsumen

\subsection{Margin Pemasaran Ikan}

Margin pemasaran merupakan selisih antara harga yang dibayar oleh konsumen dan harga yang diterima oleh produsen. Margin pemasaran terdiri atas dua komponen yaitu komponen biaya pemasaran dan komponen keuntungan lembaga pemasaran. Saluran pemasaran ikan yang terjadi di Kecamatan Insana Utara bervariasi sehingga margin pemasaran yang terjadi bervariasi pula sesuai dengan saluran pemasaran. Berikut adalah margin pemasaran yang terjadi di setiap saluran pemasaran.

\section{a. Margin Pemasaran pada Saluran Satu}

Pada saluran pertama ini nelayan secara langsung memasarkan ikan kepada konsumen yang berada di Kecamatan Insana Utara maupun konsumen yang berada di luar Kecamatan Insana Utara, sehingga pada saluran ini tidak menimbulkan margin pemasaran.

\section{b. Margin Pemasaran pada Saluran Dua}

Berdasarkan hasil analisis data primer margin pemasaran yang terjadi pada saluran ini dapat di lihat pada Tabel 2.

$\underline{\text { Tabel 2. Distribusi Margin Pemasaran di Pengecer Wini }}$

\begin{tabular}{clcc}
\hline \multirow{2}{*}{ No } & \multicolumn{2}{|}{ Jenis Ikan } & \multicolumn{2}{c}{ Pengecer } \\
\cline { 3 - 4 } & & Margin $(\mathrm{Rp})$ & $\%$ \\
\hline 1 & Tembang & 150000 & 27,27 \\
3 & Kombong & 200000 & 22,22 \\
4 & Nipi & 250000 & 33,33 \\
\hline
\end{tabular}

\section{c. Margin Pemasaran pada Saluran Tiga}

Berdasarkan hasil analisis data primer pada saluran ini nelayan menjual ikan ke pedagang pemborong Wini, kemudian pemborong Wini menjual ke pengecer yang berasal dari Atambua dan Kefa. Margin pemasaran yang terjadi berbedabeda tergantung dari jenis ikan. Margin pemasaran ikan yang terjadi pada saluran dapat dilihat pada Tabel 3 .

Tabel 3. Distribusi Margin Pemasaran Ikan di Tingkat Pedagang Perantara Wini

\begin{tabular}{clcccccc}
\hline \multirow{2}{*}{ No } & \multirow{2}{*}{ Jenis Ikan } & \multicolumn{2}{c}{ Pemborong } & \multicolumn{2}{c}{ Pengecer } & \multicolumn{2}{c}{ Total Margin } \\
\cline { 3 - 8 } & & $\mathrm{Rp}$ & $\%$ & $\mathrm{Rp}$ & $\%$ & $\mathrm{Rp}$ & $\%$ \\
\hline 1 & Tembang & 150000 & 27.27 & 205000 & 27.15 & 355000 & 47.01 \\
2 & Kombong & 200000 & 22.22 & 180000 & 16.66 & 380000 & 35.18 \\
3 & Nipi & 200000 & 28.57 & 210000 & 23.07 & 410000 & 45.05 \\
4 & Tongkol & 200000 & 33.33 & 220000 & 26.82 & 420000 & 51.21 \\
\hline
\end{tabular}

\section{d. Margin Pemasaran pada Saluran Empat}

Pada saluran ini pemborong yang berasal dari kefa membeli ikan di nelayan yang berada di Kecamatan Insana Utara, kemudian pemborong menjual ikan kepada pengecer Kefa dan pengecer Kefa menyalurkan kepada konsumen Kefa. Margin pemasaran ikan yang terjadi pada saluran dapat dilihat pada Tabel 4.

\begin{tabular}{clcccccc}
\multicolumn{2}{c}{ Tabel 4. Distribusi Margin Pemasaran pada Pedagang Perantara Kefa } \\
\hline \multirow{2}{*}{ No } & \multirow{2}{*}{ Jenis Ikan } & \multicolumn{2}{c}{ Pemborong } & \multicolumn{2}{c}{ Pengecer } & \multicolumn{2}{c}{ Total Margin } \\
\cline { 3 - 8 } & & $\mathrm{Rp}$ & $\%$ & $\mathrm{Rp}$ & $\%$ & $\mathrm{Rp}$ & $\%$ \\
\hline 1 & Tembang & 200000 & 33.33 & 150000 & 20 & 350000 & 46.66 \\
2 & Kombong & 250000 & 26.31 & 110000 & 10.37 & 360000 & 33.96 \\
3 & Nipi & 250000 & 33.33 & 150000 & 16.66 & 400000 & 44.44 \\
4 & Tongkol & 200000 & 33.33 & 180000 & 23.07 & 380000 & 48.71 \\
\hline
\end{tabular}

\section{e. Margin Pemasaran pada Saluran Lima}

Pada saluran ini pemborong yang berasal dari Atambua membeli ikan di nelayan di Kecamatan Insana Utara, kemudian pemborong menjual ke pengecer Atambua dan pengecer menyalurkan ikan kepada konsumen Atambua. Margin pemasaran yang terjadi pada saluran ini berbeda-beda. Margin pemasaran ikan yang terjadi pada saluran dapat dilihat pada Tabel 5.

$\underline{\text { Tabel 5. Distribusi Margin Pemasaran pada Pedagang Perantara Atambua }}$

\begin{tabular}{clcccccc}
\hline \multirow{2}{*}{ No } & \multirow{2}{*}{ Jenis Ikan } & \multicolumn{2}{c}{ Pemborong } & \multicolumn{2}{c}{ Pengecer } & \multicolumn{2}{c}{ Total Margin } \\
\cline { 3 - 8 } & & $\mathrm{Rp}$ & $\%$ & $\mathrm{Rp}$ & $\%$ & $\mathrm{Rp}$ & $\%$ \\
\hline 1 & Tembang & 200000 & 33.33 & 160000 & 21.05 & 360000 & 47.36 \\
2 & Kombong & 250000 & 26.31 & 150000 & 13.63 & 400000 & 36.36 \\
3 & Nipi & 250000 & 33.33 & 170000 & 18.47 & 420000 & 45.65 \\
4 & Tongkol & 250000 & 38.46 & 210000 & 24.41 & 460000 & 53.48 \\
\hline
\end{tabular}

\section{Simpulan}

Terdapat lima saluran pada pemasaran ikan di Kecamatan Insana Utara yang melibatkan nelayan dan pedagang perantara. Pedagang perantara yang terlibat dalam pemasaran ikan di Kecamatan Insana Utara yaitu pedagang pemborong Wini, pedagang pemborong Kefa, pedagang pemborong Atambua, pedagang pengecer Wini, pedagang pengecer Kefa, pedagang pengecer Atambua. Fungsifungsi pemasaran yang dilakukan oleh nelayan adalah fungsi penjualan, fungsi pengadaan fisik dan fungsi informasi pasar. Sedangkan fungsi pemasaran yang dilakukan oleh pedagang pemborong yakni fungsi pembelian, fungsi penjualan, fungsi pengadaan fisik dan fungsi informasi pasar, sedangkan fungsi pemasaran yang dilakukan oleh pedagang pengecer yakni fungsi pembelian, fungsi penjualan, fungsi pengadaan fisik dan fungsi grading. Margin pemasaran yang terjadi di setiap saluran pemasaran berbeda-beda, margin pemasaran yang terjadi pada pedagang pemborong Wini untuk ikan tembang sebesar Rp 150.000, ikan Kombong sebesar Rp 200.000, ikan Nipi sebesar Rp 200.000 dan ikan Tongkol sebesar Rp 200.000 sedangkan margin pada tingkat pengecer Kefa yang membel ikan dari pemborong Wini, untuk ikan Tembang sebesar Rp 205.000, ikan Kombong sebesar Rp 180.000, ikan Nipi sebesar Rp 210.000 dan ikan Tongkol sebesar 220.000. Margin pemasaran yang terjadi pada pemborong Kefa untuk ikan Tembang sebesar Rp 200.000, ikan Kombong sebesar Rp 250.000, ikan Nipi sebesar Rp 250.000 dan ikan Tongkol sebesar Rp 200.000. Sedangkan margin pemasaran pada tingkat pengecer untuk ikan Tembang sebesar Rp 150.000, ikan Kombong sebesar Rp 110.000, ikan Nipi sebesar Rp 150.000 dan untuk ikan Tongkol sebesar Rp 180.000. Margin pemasaran yang terjadi pada pedagang pemborong atambua untuk ikan Tembang sebesar Rp 20.000, ikan Kombong sebesar Rp 250.000, ikan Nipi sebesar Rp 250.000 dan ikan Tongkol sebesar Rp 250.000. Sedangkan di tingkat pengecer untuk ikan Tembang sebesar Rp 160.000, ikan Kombong sebesar Rp 150.000, ikan Nipi sebesar Rp 170.000 dan untuk ikan Tongkol Rp 210.000.

\section{Pustaka}

Azzaino, Z. 1982. Pengantar Tataniaga Pertanian. Bogor: Fakultas Pertanian IPB.

[BPS] Badan Pusat Statistik, 2015. Timor Tengah Utara dalam Angka Kefamenanu.

Subagyo, P.J. 2006. Metode Penelitian dalam Teori dan Praktek. Jakarta: Rineka Cipta.

Sudiyono, A. 2002. Pemasaran Pertanian. Malang: Universitas Muhamadiyah. Sugiyono. 2006. Metode Penelitian Kuantitatif, Kualitatif dan $R \& D$. Bandung. Alfabeta.

Undang-Undang Republik Indonesia Nomor 45 Tahun 2009 tentang Perubahan Atas Undang-Undang Nomor 31 Tahun 2004 tentang Perikanan. 